\title{
A PARTICIPAÇÃO JUDAICA NA CARTOGRAFIA MEDIEVAL MAIORQUINA.
}

\author{
Magali Gomes Nogueira*
}

\section{Resumo}

O presente artigo tem como objetivo apresentar considerações a respeito das fontes utilizadas para a construção do Padrão Portulano, gênero cartográfico entendido como de vital importância para o desenvolvimento da ciência cartográfica, uma vez que essa construção resulta de um longo processo de compilação e comprovação de dados astronômicos e geográficos que foram sendo acumulados pelos estudiosos desde o inicio da escrita. Sendo considerado como um "Renascimento Cultural", o momento de sua produção, os séculos XIII e XIV foi marcado por um intenso processo de Disputas entre as tradições que contribuíram para sua realização, os islâmicos, hebreus e cristãos. Disputas estas que se encontram em forma de livros e textos representados nas bibliotecas encontradas em Maiorca, entendida comoo local da última etapa desta produção, materializada no famoso "Atlas Catalão" e nas Cartas Portulano maiorquinas.

*Doutoranda pelo Departamento de Geografia da USP. 


\section{Introdução}

A Cartografia produzida pela Aljama judaica maiorquina, ao longo do século XIV, tem sua materialização gráfica atribuída ao obrador da família do judeu Cresques Abraham e mereceu destaque na História da Cartografia Medieval devido à existência de um inventário relativamente pequeno, de exemplares de luxo da representação cartográfica do plano Mediterrâneo, que se convencionou chamar Padrão Portulano, com enfoques geográficos diferenciados em relação ao meridiano de origem, ainda que as variações sejam pequenas devido à proximidade geográfica dos meridianos estabelecidos, como Pisa, Barcelona, Montpellier. O mais famoso entre eles, o "Atlas Catalão" ${ }^{1}$, tem atribuído ao mesmo Cresques Abraham sua beleza pictórica e o emprego de materiais como folhas de ouro e prata. Esse gênero cartográfico, Padrão Portulano, tornou-se importante devido à extrema precisão com que o perfil mediterrâneo foi traçado. Entre seus principais estudiosos encontram-se Rey Pastor, Tony Campbell, Ramón Pujades i Bataller, entre outros.

Estes autores debatem o como se obteve a precisão geográfica que essa construção apresenta em relação ao Mediterrâneo e qual o conhecimento necessário para sua produção gráfica, assim como quem foram seus agentes e em que contexto material se concretizou. Algumas características deste momento, que o levaram a ser entendido como um "renascimento cultural" (séculos XI/XIII) indicam a continuidade dada pelos árabes ao estudo da forma e das dimensões do espaço, a "ciência grega" recebida através de Ptolomeu. Herdeiro da tradição aristotélica de espaço finito, o longo processo de divisão da esfera que a forma do Mundo indicava, convencionada em $360^{\circ}$, entrelaçada pela evolução do ano solar e dos planetas, chega a Península Ibérica, acrescido das inovações trazidas pelos árabes, a divisão decimal e o zero e ocasiona na Europa ocidental uma febre de racionalização do espaço e padronizações de pesos e medidas possibilitando que, entre outros benefícios, todos os sábios e estudiosos trabalhassem com instrumentos que fizessem as mesmas medidas e

\footnotetext{
1“Atlas Catalão" pode ser considerado um nome fantasia dado pelos estudiosos ao documento catalogado na seção de Manuscrito da Biblioteca Nacional da França, em Paris, sob a assinatura Manuscrito Espagnol 30 (Ms.Esp.30), devido à língua em que foi escrito, ou seja, o Catalão e por possuir um belíssimo mapa-múndi em quatro das seis folhas que o compõe. No texto a seguir, usa-se sua assinatura para referências a este exemplar, base deste artigo.
} 
pudessem corrigir a localização do ponto geográfico dentro do mesmo método de conversão das triangulações celestes.

Esta geometria matemática será apropriada e aplicada pela Astronomia e pela Geografia na representação de seus objetivos, ou seja, a evolução dos astros e suas infinitas combinações, acompanhada do ponto de vista humano e a localização do plano terrestre a partir de referências astronômicas, respectivamente. No Padrão Portulano, materializa-se este conhecimento em rede de ventos ou direções entrelaçadas sobre um suporte, permitindo visualizar mais facilmente a latitude e a longitude dos pontos geográficos assinalados sobre o plano das coordenadas terrestres, simbolizadas por paralelos e meridianos. No Ms.Esp.30, materializa-se na Rosa dos Ventos com 32 direções. Essa evolução matemática, aplicada às ciências naturais, permitirá a independência da geográfica em relação à astronomia podendo, pensar-se a representação do espaço dentro de lógicas matemáticas que compensam a esfericidade da forma terrestre, a projeção cartográfica, considerada a partir de então, ciência.

O que se pretende neste artigo, a partir de uma rápida contextualização da Aljama judaica maiorquina, será apresentar possíveis fontes hebraicas e estudiosos judeus que tenham participado deste momento científico, em que a posse de territórios ao norte da África e ao sul da Península Ibérica, ao redor da bacia mediterrânea, passa dos godos e visigodos para os árabes e africanos e destes para os ibéricos, universalizando um conhecimento que os árabes do Islã tomam como principio religioso, ou seja, a matemática da Criação. Conhecimento compilado e traduzido em Bagdá, recebendo contribuições das verificações astronômicas que atualizam dados e corrigem posições geográficas nas tabelas astronômicas herdadas dos alexandrinos e que, ao adentrar nos meios filosóficos e científicos existentes na Europa Ocidental, ocasionam momento de intensa troca entre as três tradições que o promovem, islâmicos, hebreus e cristãos.

\section{A Aljama maiorquina.}

Maiorca, a maior das Ilhas Baleares, desde os tempos do Império Romano, apresenta-se com destaque no comércio marítimo entre o Ocidente e o Oriente, aumentando sua participação quando passa a ser a ilha oriental da Andaluzia, integrando-se ao comércio realizado pelas ilhas e cidades italianas como Sicilia, Pisa, Genova e Veneza, neste momento aliadas pelo interesse econômico aos comerciantes árabes, objetivando abrir frentes em 
direção ao Atlântico e às nações do Atlântico Norte. Durante o processo de expulsão dos árabes dos territórios ocupados ao sul da Península Ibérica, Maiorca passa ao domínio da Coroa Catalã Aragonesa, na pessoa de Jaime I de Aragão (1229), tendo sua atividade comercial redimensionada, agora em direção ao norte da França, passando a constituir-se em importante centro distribuidor dos tecidos produzidos no norte da França, entre outros produtos, levando a uma diminuição da importância que as rotas terrestres representavam para a economia da região.

Esse importante papel distribuidor dos produtos e matérias primas, oriundas do norte da Europa e do Oriente, em direção à um Atlântico em definição, foi fator decisivo no processo de construção do gênero cartográfico Portulano, colocando a navegação como elemento importante na precisão do perfil desenhado que, por sua vez, contribuirá para uma maior agilidade e eficiência do comércio marítimo ${ }^{2}$, para o conhecimento da forma da Terra e para o estabelecimento da projeção cartográfica como um evento da ciência moderna.

Aliado ao aspecto econômico de Maiorca, com participação efetiva de membros da comunidade judaica, também relacionados à administração da Coroa Catalã Aragonesa ${ }^{3}$, encontra-se documentado na ilha a existência de ofícios e estudiosos relacionados à evolução das ciências naturais, do instrumental necessários para medições, bibliotecas particulares que atestam intensa participação desta comunidade na continuidade do aperfeiçoamento técnico da divisão do espaço e sua representação gráfica, o desenho da Terra conhecida, como o feito pelo judeu Cresques Abraham no Ms.Esp.30.

Um dos momentos auge desta comunidade sob o comando cristão será, justamente, nos reinados de Fernando III e Alfonso X, em Castela, com a ocorrência do fato histórico conhecido como Escola de Tradutores de Toledo e entre os reinados de Jaime I e Pedro IV de Aragão quando se intensificam os estudos talmúdicos nas aljamas de várias cidades, como Segóvia, Gerona, Tudela, e Valência, verdadeiros focos de produção do conhecimento, aliando práticas como a compilação e tradução dos antigos tratados filosóficos trazidos do Oriente pelos islâmicos, com a atualização de dados resultantes da observação da natureza e ofícios relacionados à produção material e instrumental necessários para o registro dos novos conhecimentos e dos dados relativos à administração e negócios dos novos reinos.

\footnotetext{
${ }^{2}$ LANE, 1963, p.605-617.

${ }^{3}$ ROMANO, 1996. ROMANO, 1983. CAUTEURA BENNASSSER, 1989. p.49-60.
} 
Várias personalidades judaicas relacionadas à produção do conhecimento viveram na Catalunha deste período: Nahmánides, Abraham bar Hiyya, Ibn Ezra, Yoná Gerundí, Yehudá ben Barzilay al-Bargeloní, os rabinos Selomó ben Adret e Ishaq bar Séset, os cabalistas Ezra ben Selomó y Azriel de Gerona, os filósofos e físicos Leví ben Abraham ben Hayyim, Leví ben Gerson, Ishaq Albalag e Hasday Cresques, entre outros poetas e escritores.

Mas, o que vem a ser o gênero cartográfico Portulano e como se deu sua construção? Entre os estudiosos pode-se perceber certo consenso na resposta à primeira questão, não ocorrendo o mesmo em relação aos métodos e agentes de sua construção, como veremos a seguir.

\section{Tipologias e Definições}

De maneira geral, o Padrão Portulano está descrito como uma representação gráfica em escala e de maneira realista da bacia Mediterrânea, feita sobre uma superfície plana (geralmente pergaminho) cruzada por uma rede de linhas construídas a partir das direções dos ventos, sendo sua finalidade facilitar a navegação e determinar com precisão a localização dos portos existentes em torno desta bacia, a partir da utilização de bússola e compasso como instrumentos de navegação. Essa definição parte do pressuposto de que o objetivo principal destas representações seria instruir marinheiros que não teriam o conhecimento necessário para se localizarem a partir da identificação dos pontos celestes em astrolábios, normalmente utilizados para localização em travessias, tanto marítimas como terrestres.

Outra característica comum é a utilização do pescoço do pergaminho sempre voltado para a esquerda (oeste) e a Flor de Lis que encima a Rosa dos Ventos, indicando o norte. Na maioria deles encontra-se também uma cruz indicando o leste, em menção à Terra Sagrada para as três civilizações, árabes, judeus e cristãos, que haviam produzido o conhecimento necessário para a construção das Cartas Portulano. Quanto à Flor de Lis, alguns a entendem como sendo uma homenagem aos Bourbon, casa francesa, que a utilizam em seu escudo de armas, outros a entendem como um símbolo hebraico constante do Pentateuco.

O gênero cartográfico Portulano também terá um papel inovador no plano da linguagem cartográfica, pois nele serão introduzidos símbolos procurando universalizar sua leitura como, por exemplo, padrão de escala, linhas de rios esboçados suavemente, nome dos principais 
portos e cidades em vermelho, perpendicular à costa, nome dos mares dentro de moldura colorida, no interior, desenhos padronizados de cadeias de montanhas, rotas, vilas e cidades indicadas por signos e bandeiras retratando suas soberanias, indicativa do caráter político dessas representações. Confirmando as hipóteses de que auxiliavam na navegação, trazem também sinais indicativos de bancos de areias e outros acidentes geográficos assim como podem indicar povos e hábitos que facilitem o contacto dos comerciantes.

Em termos de tipologia, algumas subdivisões são sugeridas pelos estudiosos. A Carta Portulano, entendida a partir da descrição feita acima, pode apresentar-se sob as denominações de "simples", "normais" ou "puras" quando se apresentam apenas com o padrão Portulano. Quando a este padrão são acrescidas informações a respeito de aspectos culturais, políticos, produtos, flora e fauna das regiões representadas, recebem a denominação de cartas de luxo (Pujades i Bataller) ou cartas geográfico-culturais (Rey Pastor). Pujades i Bataller (2008) ainda estabelece uma divisão na classificação quanto à decoração e características geográficas. Em termos de decoração as representações podem apresentar uma hierarquia que vai do luxo à representação simples, variando de acordo com a quantidade de ouro e miniaturas empregadas na confecção de seu programa pictórico.

Quanto aos aspectos geográficos, identificam-se cinco categorias: o Mapa-múndi Portulano representativo de todo o mundo conhecido, a carta Portulano inteira, em que aparecem representados o Mediterrâneo e o Mar Negro, com alguns subtipos em que podem aparecer a Escandinávia e o Mar do Norte ou o Atlântico, a Carta Parcial, que incluiria parte do Mediterrâneo, variando quanto à representação da Península Ibérica e do norte da África, a Carta Atlântica, após o século XV, na qual aparecem representada as costas atlânticas da Europa e da África e parte do Mediterrâneo até as Baleares e, finalmente, a Carta Adriática, na qual é representado apenas o Mar Adriático e suas conexões, aparecendo como carta independente após 1459, comum nos atlas produzidos em Veneza.

Utiliza-se a voz Carta para os exemplares de uma só folha, talvez devido à tradição medieval que a relaciona com as representações utilizadas pela cartografia marítima e de navegação. Se a palavra Carta vem do grego Kartes, que significa pergaminho, papel ou um suporte para a escrita, pode-se pensar que quando os "homens navegantes" 4 do Mar Mediterrâneo dizem Carta de marear ou de navegar, no processo de estabelecer um código de comunicação comum a todos, querem dizer uma representação, no plano, das costas

\footnotetext{
${ }^{4}$ Expressão empregada pelo autor do MS. Esp.30.
} 
mediterrâneas, dos portos, acidentes geográficos e, principalmente, de suas rotas de comércio. A palavra Carta é também entendida como o registro diário da experiência vivida e das reflexões feitas pelo mercador durante sua viagem a um interlocutor constante, mantido no porto, comunicação permitida pelo entra e sai dos navios ${ }^{5}$.

O uso da palavra Portulano se deve a irrefutável influência da prática náutica na construção deste padrão, ainda que não pareça possível ser fruto apenas desta prática. Pelo que se sabe até agora a denominação "Portulano" para este tipo de produção cartográfica foi consignada pela primeira vez pelo Visconde de Santarém (1844).

$\mathrm{Na}$ historiografia especializada consta que esse tipo de produção cartográfica recebia, no momento de sua produção, a denominação de carta náutica, carta de marear ou marítima, aparecendo também a denominação de “compás" 6 , estando reservada a denominação de Portulano aos Livros de Derrota ou Livros de Bordo. Os Livros Portulanos, transportados pelos pilotos nas embarcações que cruzavam o Mediterrâneo eram, então, livros em que se anotavam as distâncias percorridas, as rotas, os rumos e os acidentes no trajeto por onde os navios mercantes passavam com suas mercadorias. Em termos cartográficos, a expressão derrota significa o ângulo entre o norte e a linha tangente à rota do navio. Estes livros também podiam conter anotações referentes à entrada e saída de mercadorias no navio; mortes ou outros acidentes durante a viagem, feitas pelo escrivão de bordo.

Assim como as anotações astronômicas e de navegação feitas nos Livros de Derrota estão relacionadas à construção das representações cartográficas medievais, pela observação e precisão das distâncias e direções percorridas, as anotações sobre entradas e saídas de mercadorias e ocorrências a bordo também serão utilizadas em outros tipos de literatura desenvolvida no período, como a Literatura de Viagem, os Manuais de Mercadoria e os Livros de Contabilidade.

Os mapas-múndi medievais, ainda que o $\operatorname{luxo}^{7}$ varie nos exemplares remanescentes, caracterizam-se por trazer em iluminuras ou Miniaturas, iconografia que revela dados

\footnotetext{
${ }^{5}$ Cowan, 1996. Obra exemplar deste tipo de produção literária relacionada ao entra e sai dos navios com informações a respeito do mundo que se está cartografando.

${ }^{6}$ Mencionado por REY PASTOR e GARCIA CAMARERO (1960), provavelmente pelo uso obrigatório do compasso de ponta para a determinação da distância entre os dois pontos a ser percorrido. Em seu capitulo I realiza extensa análise sobre as diversas denominações da tipologia relativa às cartas náuticas.

7 "Luxo" não só no sentido da sofisticação dos materiais empregados na sua confecção como também na quantidade de iluminuras empregadas em seu projeto gráfico. LLOMPART MORAGUES, G.
} 
relativos a regiões e pessoas, como o próprio autor do Ms. Esp. 30 nos indica em seu incipt: "Mapa-múndi, que podemos entender como imagem do mundo, de suas diversas idades, das regiões que existem sobre a Terra e das diversas gentes que ai habita” (folha 01).

Quanto à sua técnica de representação cartográfica, o mapa-múndi do Ms.Esp.30 pode ser entendido como transicional por mesclar uma representação referente ao Mediterrâneo, bastante precisa no sentido da localização espacial, com uma Ásia em escala indefinida e reproduzindo forma e antigas referências bíblicas e eclesiásticas usadas na representação cartográfica OT. ${ }^{8}$, ambas convivendo ao longo dos séculos XIII e XIV.

No texto do Manuscrito Espagnol 30, encontramos a palavra "Mapamondi" significando a imagem do Mundo e das regiões que estão sobre a Terra e suas gentes. A imagem, em sua descrição escrita, é a de uma "pelota", estabelecendo a clássica comparação com a forma do ovo e dos elementos que o compõem. Dessa maneira, a palavra mapa está associada à palavra imagem e mondi, à palavra latina para o Cosmos grego, o Todo que inclui as esferas celestes, a Terra, os humanos e tudo mais que os envolvem. Dessa maneira, a palavra Mapa, no contexto geral do programa pictórico do Ms.Esp.30 assume tanto o significado da representação plana do Ecúmeno como a organização hierárquica das esferas que compõem o todo no qual a Terra estaria inserida como centro.

A menção mais antiga que se conhece da utilização da carta de marear encontra-se nas "Crônicas do rei Luiz IX" 9 , nos relatos referentes à Oitava Cruzada, saída de Águas Mortas, em 1270. A partir deste momento esta cidade, situada às margens de uma imensa laguna que se comunica com o Mediterrâneo e o Rio Ródano por canais, passa a exercer um papel importante na composição política e na organização comercial da região. Quando embarca

(2010). Estudi Historicoartistic. pp.111-141 in URGELL HERNANDEZ, R. (2010), desenvolve interessante estudo relativo a preços e estilos das iluminuras e da profissão de iluminador durante o século XIV a partir do Llibre des Franqueses, Codex .I., sob a custódia do ARM. Palma, Maiorca.

${ }^{8}$ Produção cartográfica, que tem sua base na representação esquemática do mundo herdada da antiga Mesopotâmia, em forma de $\mathrm{O}$, a Terra circundada pela água, a esfericidade da Terra, dividida em três partes, orientação leste, com o braço vertical representando o Mediterrâneo e o braço horizontal o rio Nilo, Mar Negro e, às vezes, os rios Tigre e Eufrates. Ásia na parte superior, leste, Europa à esquerda, norte e África à direita, Sul. Produção destacada do Beato de Liebana e auge na representação de Erbstorf. Que foi lido como sendo a representação do corpo de Cristo com a cabeça a leste, às vezes simbolizada com imagens do Paraíso ou, adaptada ao momento de sua produção, a norte e sul, mãos e pés, respectivamente. Temos também manifestações cartográficas deste gênero que incorporam as informações climáticas sobre a esfera da Terra, "Orbis Terrarum" assim como conhecimentos sobre sua forma e tamanho, trazidos pelos estudiosos deste momento.

9 "Gesta S.Ludovici IX Francorum regis" publicada por DAMOU at NAUDET, T.XX, 1840, pp.309462. Em FALL Y.K. (1982), p.55. 
para a sétima Cruzada em 1248, o traçado da nova cidade está quase terminado. A partir da Oitava Cruzada, Águas Mortas torna-se um centro de intercâmbios comerciais de primeiro plano entre o ocidente e os países do Nascente, sendo determinante na diminuição da importância das rotas comerciais terrestres.

Depois desta, encontra-se a menção feita por Raimundo Llull ${ }^{10}$, considerada a primeira em terras catalãs, que em seu livro Fênix das Maravilhas da Cidade, em 1286, diz que os navegantes de seu tempo utilizavam "instrumentos de medida, de cartas marítimas e de agulha imantada".

Encontra-se também menção no inventário de bordo de um navio siciliano que se fez ao mar em 1293, em Taranto, o São Nicolau de Messina, que assim descreve três $\operatorname{cartas}^{11}$ :

Mappemundum unum cum compasso, tar. 07 et gr.10 (um mapa-mundi com compasso Valendo 7 tarins e 10 gros.)

Mappamundum unum tar. 06 (um mapa-mundi valendo 06 tarins)

Mappamundum unum tar. 07 (um mapa-mundi valendo 07 tarins)

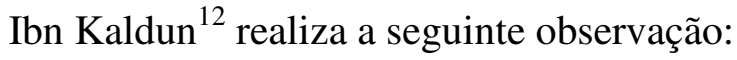

Todas as localidades situadas nas duas margens do Mediterrâneo encontram-se desenhadas em uma folha de acordo com sua verdadeira forma e a desproporção que apresentam junto à orla do mar. As pontas desde onde sopram os ventos e as distintas direções que seguem estão indicadas nesta folha a que chamam compasso - não existe quando se trata do Atlântico, razão pela qual os navegantes não se atrevem a lançar-se Oceano a dentro posto que, se perderem de vista as costas não saberiam como voltar ao ponto de partida.

Durante os séculos contemporâneos ao surgimento desta produção cartográfica as referências existentes são vivas, isto é, são referências relativas a pilotos que as usam e detectam problemas em suas indicações e exigem atualizações dos dados. São estudiosos que aperfeiçoam suas formas, são reis e mercadores que investem em sua produção para possibilitar viagens mais seguras, quando simples, ou como objetos de presente e posição

\footnotetext{
${ }^{10}$ Raimundo Llull, doutor espiritualista nascido em Maiorca, (1235-1315) filho de uma rica família de mercadores, prega a conversão filosófica. Terá mais seguidores em Valência e Barcelona do que em Maiorca. Deu aulas em Paris para os beguinistas (seguidores do beato). Funda na Ilha a Escola de Artes Miramar que deixa aos cuidados de Guillen de Vilanova, provável "rector" da Cidade de Maiorca. Sua "Escola" produziu a tradução de diversos textos árabes na ilha e, após sua morte, instituiu-se três centros de difusão de sua obra: Paris, Genova e Maiorca.

${ }^{11}$ FALL, Y.K. (1982), L`Afrique à la naissance de la cartographie moderne. Les cartes majorquines: XIV-XV siècles. París: Karthala.p. 59

${ }^{12}$ Carta Magrebina. 1330. Apresenta um conhecimento do mundo mais extenso do que o da Carta Pisana. FALL, (1982) p.14. A informação esta referenciada ao viajante Ibn Kaldun.
} 
social, devido a seu alto custo, quando de luxo, são viajantes que descrevem as riquezas dos locais visitados, úteis tanto a comerciantes como a conquistadores.

É o momento das traduções de antigos compêndios astronômicos e astrológicos, de atualizações das tábuas astronômicas, bastante populares, dos tratados aperfeiçoando e ensinando a construção de astrolábios planos, das bússolas e das rosas dos ventos, indicando direções, inserindo-se em uma concepção de mundo, em debate constante pela filosofia, que afirma os vínculos existentes entre as esferas terrestres e celestes. É o que se pode entender como ciência medieval. Processo este, em termos geográficos, materializado nos tratados dos séculos XVI e XVII de Pedro Nunes e Mercator com a apresentação de uma projeção alternativa à construção do Padrão Portulano, conquistando para a Cartografia o status de ciência.

\section{A Produção Cartográfica Maiorquina.}

O processo de construção do padrão Portulano e quais teriam sido seus agentes é objeto de algumas divergências entre os estudiosos uma vez que a maioria dos exemplares, produzidos durante os séculos XIII e XIV, não era assinada. O exemplar considerado como o remanescente mais antigo de que se tem noticia, a Carta Pisana, recebeu esse nome devido ao local onde foi encontrada e catalogada, sendo datada do final do século XIII, provavelmente 1275. Pelo fato das mais antigas Cartas Portulano conterem toponímias italianas, foram consideradas obras de navegantes e estudiosos das cidades de Pisa, Genova e Veneza, ocasionando mesmo uma acirrada disputa, durante o século XIX, sobre sua nacionalidade, momento em que essa produção está sendo recuperada com objetivos de definições territoriais, após o evento napoleônico e, mais especificamente, na questão das possessões coloniais africanas, durante disputa ocorrida entre Portugal, França e Bélgica pela legitimação de suas conquistas.

A produção cartográfica maiorquina, em Inventário que identifica apenas 31 exemplares remanescentes, em sua maioria, também não se encontra assinada. A atribuição de autoria do seu exemplar mais famoso, o "Atlas Catalão", foi realizada a partir de investigações feitas nos arquivos existentes tanto em Maiorca como em Barcelona, baseada em documentos que identificam à Cresques Abraham e membros de sua família, como seu 
filho Jafuda Cresques, como os “mestres em cartas de marear" existentes na Ilha no período em que estas Cartas foram produzidas.

O estudo realizado sobre esta família ${ }^{13}$ aponta para a existência de uma comunidade judaica bastante atuante na Ilha, com boas bibliotecas, mantendo antigas tradições jurídicas e religiosas, desenvolvidas desde os tempos da dominação árabe, relacionando sua produção aos estudiosos das regiões de Valência, Barcelona, Montpellier, Gerona e outras localidades em que as comunidades judaicas existentes são tidas como atuantes e produtoras de conhecimento, não só no plano interno aos interesses judaicos como também voltadas para atividades que buscam compreender a forma e a racionalidade do que então é entendido como a “natureza da Criação”.

As personalidades e as Bibliotecas existentes na Aljama de Maiorca, apontadas por este estudo, indicam hipóteses não muito comum na bibliografia existente sobre método de construção e agentes produtores do Padrão Portulano, que busca suas origens em antigos escritores relacionados à Patrística, além dos escritos de pensadores gregos introduzidos na Península a partir da invasão árabe, como Aristóteles e Ptolomeu, apontando a concretização gráfica do perfil mediterrâneo como responsabilidade dos homens navegantes ao registrarem rotas, rumos e distancias em seus Livros de Derrota (ou Portulano). A inserção da comunidade judaica neste processo dá-nos a dimensão de um processo contínuo de transmissão, ocorrendo no momento da construção do padrão Portulano uma releitura de antigos mestres dos séculos XII e XII, como Ibn Ezra ou Maimônides, que, por sua vez, trabalham sobre os textos gregos traduzidos e acrescidos em Bagdá, possibilitando um importante momento de síntese significativo para a ciência cartográfica.

Ao espaço convencionado da Terra, igual a uma esfera de $360^{\circ}$ dentro de uma tradição que remonta a Euclides, século III a.C, acrescentaram-se observações e complementações da Geografia, Astronomia e Geometria, sintetizadas por Ptolomeu, que organiza o saber recebido em seu Planisférium, explicitando sua técnica para construção de representações cartográficas. Considera o desenho do plano terrestre como resultado da ação geográfica de localizações de pontos dentro de uma quadrícula de paralelos e meridianos a partir de triangulações celestes, desenvolvidas pela Astronomia e aplicadas à superfície terrestre pelos geômetras, que também podiam ser chamados de mestres da imagem, título dúbio que às

\footnotetext{
${ }^{13}$ NOGUEIRA, 2013, p. 138-158. Base: www.cresque.net
} 
vezes pode ser entendido não como aquele que faz cálculos e representações gráficas perfeitas, mas como o pintor da imagem.

A divisão do espaço em ventos intermediários entre posições geográficas também pertence à tradição ptolomaica, que aperfeiçoou a técnica de divisão das formas geométricas, iniciada com a construção das formas dos corpos naturais (celestes) pelos antigos babilônios e egípcios, evoluindo para a abstração precisa do ser geométrico, na linguagem medieval. Essa técnica de construção de formas a partir de pontos e linhas será base de várias áreas do saber como a Agrimensura, Topografia, Astronomia, Geografia e da Geometria.

Inicialmente usada para divisões das terras, a geometria permite estabelecer correspondência entre os pontos celestes e terrestres, aperfeiçoando a prática de construção de tabelas em que pontos celestes e sua contrapartida terrestre são relacionados com indicações de latitudes e constelações correspondentes (as Tábuas Geográficas e Astronômicas).

O catálogo de estrelas e pontos geográficos de Ptolomeu já confirmava a cifra de 1022 estrelas, com brilho, movimento e correspondência terrestre. A imagem que a teoria de Ptolomeu permite desenhar do plano mediterrâneo (o Ecúmeno), reproduzida a partir do século XIII, será muito próxima à produzida pelo padrão Portulano, se respeitados os mil anos de aperfeiçoamento desta imagem que separam as duas produções.

A tradição ptolomaica também inclui entre seus temas o aperfeiçoamento de instrumentos como astrolábios e quadrantes, proporcionando uma precisão maior no constante aumento de pontos verificáveis nas Tábuas Astronômicas e Geográficas, acrescentando um novo saber na relação de ofícios para a construção do Padrão Portulano, ou seja, a Óptica que permite ampliar e precisar o campo de visão dos observadores do céu.

Acrescentar e confirmar novos pontos terá contribuição significativa na atividade cultural estabelecida entre islâmicos, hebreus e cristãos na Península Ibérica, quando foi intensificada a prática experimental de observação e produção de instrumentos. As obras de Ptolomeu, Planisferium, o Livro II da Geografia e o Tratado a respeito dos Fundamentos da Astronomia, mais conhecido como Almagesto, estão presentes na Biblioteca da Aljama de Maiorca.

Além de Ptolomeu, na Biblioteca da Aljama encontram-se outros textos e autores que se preocupam com instrumentos e precisão nas localizações, como os textos de Al-Saffãr, Astrolábio, de Raschi, o produtor de mapas de Jerusalém, as atualizações das tábuas astronômicas de Al-Battãni, de Ibn Ezra sobre Astronomia e Astrolábios, os Comentários de 
Samuel Motot sobre o Tratado de Astronomia de Ptolomeu, A forma da Terra de A. Bar Hyya, bastante popular durante o século XVI, a partir da edição que dele faz Sebastião Munster, Microcosmos, de Yosef ibn Saddiq (Joseph ibn Çaddik), além de Maimônides, Gabirol, Aharon Há-Cohen e, logicamente, Aristóteles representado pela Meteorologia e Metafísica.

É um bom quadro de pensadores. Ainda que apresentem divergências em relação a aspectos da natureza divina, concordam em medir e quantificar a Criação para alcançar o desenho mais perfeito possível de sua forma, buscando o aperfeiçoamento do Astrolábio planificado, entendido como técnica necessária para uma perfeita representação da imagem da Terra, utilizando cálculos matemáticos, cujos princípios vieram com a tradição ptolomaica.

Torna-se necessário esclarecer que essa tradição decorrente da ciência grega será apropriada pelos estudiosos dos séculos XI/XIV dentro da leitura que o monoteísmo impõe à teoria do movimento eterno, relacionando-a as emanações entre as esferas divina e terrestre, instaurando tempo e ordem em algo que se pretendia em eterno movimento. Mediada e entendida pela razão humana, a concepção de Microcosmos que repetem o sistema que coordena o Todo em suas partes, ou seja, em qualquer parte da Terra, teremos levante e ocaso e a linha do Equinócio poderá ser demarcada para o estabelecimento do plano, como o constante refazer dos elementos constituintes em formas e matérias adaptadas ao local em que ocorrem os fatos, para alguns, decorrente do arranjo cósmico dos diversos elementos, enquanto para outros passa pela vontade divina, aspecto extremamente importante na discussão medieval e que aqui não será explorado.

\section{Pensadores hebreus e comunidades do saber.}

Entendendo que a técnica do padrão Portulano tem no desenvolvimento dos cálculos matemáticos e geométricos sua principal base, pode-se estabelecer um início na pessoa do Califa Al-Mansur ${ }^{14}$ (772) que ordena a seus estudiosos aprofundarem-se na ciência do sábio hindu Sindhind ${ }^{15}$ e em seu tratado a respeito do movimento das estrelas, que será traduzido ao

\footnotetext{
${ }^{14}$ A base é o livro de Sa'id, Cadi de Toledo, Libro de las Categoria de las naciones, sobre a genealogia da ciência árabe na Espanha, citado por Millás Vallicrosa.(1960)

${ }^{15}$ Sistema Sindhind (obra astronômica de Brahmagupta, ou seja, o Brahmasiddhanta, escrito em 628) dos autores hindus: para compensar a inexatidão da divisão da esfera em relação ao ano solar, além da quarta parte adicionam uma fração de 1/120 parte do dia, ou seja, 1/5 de hora, de modo que a parte a adicionar será de $93^{\circ}$, sistema usado por Muhammad ibn
} 
árabe por Muhammad ibn Ibrahim al-Fazari, recebendo o nome "Al-Sindhind al-Kabir", base da ciência árabe até Muhammad ben Musa-al Jwarizmi, que acresce ao conhecimento árabe os números hindus e a base decimal.

Al-Jwarizmi, bibliotecário na Casa da Sabedoria de Bagdá, realiza compilações do conhecimento grego e hindu, estudos matemáticos e astronômicos, publicando tábuas astronômicas que incluíam as funções trigonométricas seno e cotangente, constando que revisou e corrigiu Ptolomeu no referente à forma da África e do Oriente. As cópias de suas compilações e estudos estiveram sempre presentes no mercado editorial. A ele foi atribuído o sistema hindu de numeração posicional em base decimal e a utilização do zero como um número a mais. Seu livro mais importante, Álgebra, foi traduzido por Gerardo de Cremona, sendo bastante divulgado entre os estudiosos das várias correntes por seu caráter didático permitir fácil compreensão dos cálculos em situações concretas como partilhas, escavações e na produção geométrica, utilizando-se da matemática grega.

Relacionado a estes primeiros contatos encontra-se Isaac Israeli, (n.855, m.950. Egito), presente na Biblioteca da Aljama, que teria vivido mais de cem anos exercendo o ofício de oculista, discípulo de Isahac ibn Imran, médico de Obeidallah, o Shiita (909-936). Entre seus escritos mais conhecidos, encontra-se o Tratado da Urina, o Livro das Febres, que expressam seu lado médico, constando uma compilação de textos de Galeno e Hipocrates finalizado com ideias e experimentos seus. Outros livros conhecidos são O Jardim da Sabedoria, em que realiza colocações metafísicas a respeito do mundo e o Livro dos Elementos, em que discorre a respeito das relações existentes entre os elementos e as esferas. Este acrescido do texto do Livro das Definições será traduzido por Gerardo Cremona e com certeza será lido por Alberto Magno, Vicente Beauvais e Tomaz de Aquino, que o referenciam em seus escritos.

A postura do Califa Al-Mansur será seguida por seus sucessores. Al-Mamum, seu filho, solicita a Al-Battãni, a tradução do Tratado sobre uso do astrolábio e atualização das antigas Tábuas astronômicas persas. A atualização e os comentários feitos por Al-Battâni são entendidos como momento importante da astrologia árabe, pois além de corrigir e atualizar empreende observações próprias em Bagdá e Damasco, ampliando o catálogo de estrelas e locais terrestres verificáveis para mais de 2000 pontos. Terá um amplo público consumidor.

Mǔsã al-Jwãrizmì.(Alcaurezmus) e por Maslama e seu discipulo Abenzafar (Abǔ-I-Qãsim Ahmad ben "Abd Allãh ben 'Umar, conocido por Ibn al Saffãr). Usada nos países cristãos. 
Este conhecimento produzido em Bagdá será levado à Córdoba por Abu-al-Qâsinn MASLAMA $^{16}$ ibn Ahmad al- Faradi al Mayriti (Madri), elo entre Córdoba, Bagdá, Egito e outras regiões do Oriente, criando grupos ou escolas de astronomias especializadas na observação de astros, manejo e construção de instrumentos de observar, corrigir, acomodar e melhorar as Tábuas Astronômicas.

Patrocinado pelo Califa Al-Hakam II (976), procurou reunir todo material disponível sobre Astronomia, aplicou-se a observar e a compreender o Almagesto. Fez recensão resumida da obra de AL JWARIZMI, adaptando-o ao árabe (antes em persa) e apontando erros. Resumiu e apontou erros nas Tabelas de Al-Battani, adaptando-as ao meridiano de Córdoba. Realizou recensão da obra de Ptolomeu em árabe (original grego perdido) entre elas o "Planisfério" traduzido ao latim por Herman, o Dálmata, talvez em colaboração com Rodolfo de Brujas. Considerado autor do famoso compendio Picatrix, conhecido e bastante editado manual de matemática ${ }^{17}$.

Herman, o Dálmata, é apresentado por Le Goff (2006) como participante do grupo de tradutores criado por Pedro, o Venerável, abade de Cluny, para realizar a tradução do Corão, publicada em 1141, sob o argumento de que seria melhor combater o islamismo pelas ideias do que pelas armas. Participavam desta equipe Robert Chester, Pedro de Toledo, da equipe de tradutores estabelecida pelo bispo Raimundo (1125-1151) e Mohammed, o Sarraceno, tido por alguns como Mosse Sefardi (citado mais adiante). Millás Vallicrosa (1973) o apresenta como um elo entre a França e o sul da Europa, sendo documentado em 1138 no norte da Espanha, onde escreve dois Tratados contra o Islão (1142); em 1143 no Languedoc escrevendo "De Essentius”, em Beziers.

As Tábuas Astronômicas de Al-Battãni serão utilizadas e atualizadas por autores de tendências e épocas distintas: como Ibn Ezra, Plato de Tivoli e Abraham Bar Hyya, que durante os anos de 1132 a 1146, em Barcelona, fizeram atualizações e versões para o latim e o hebraico, respectivamente. Maimônides a utilizará para escrever seu Tratado sobre a Santificação da Lua Nova, em sua estadia no Egito durante os anos de 1173 a 1178, revelando a popularidade destas tábuas entre os estudiosos judeus da Península Ibérica, na Corte de

\footnotetext{
${ }^{16}$ m.1008-Cordoba.

${ }^{17}$ Gayat al-Hakim significa "o acerto do sábio". Foi traduzido ao latim em 1252 com o nome de Picatrix, por ordem de Alfonso X, o Sábio. As fontes são confusas a respeito deste livro. Alguns afirmam que Picatrix foi o nome que recebeu a versão latina e outros que era o nome de seu autor, possivelmente uma corruptela de Hipocrates a quem, no Andaluz, se atribuía a paternidade da mesma.
} 
Afonso X, o Sábio, em 1275, compilado por dois astrônomos judeus, Yehudah ben Moseh e Isahq ben Said, durante o período de 1340 a 1377, pelos astrônomos judeus Imanuel Bonfils e Yom Tob Bonjorn, ativos em Provença e Roussilon, que incluíram uma tábua de "sizígias" (conjunções e oposições) verificáveis no período de março de 1361 a fevereiro de 1391, não observada por Bonjorn, uma vez que já aparece documentada em Fez, em 1344, em nome de Ibn’Azzuz al Qusanti. Bonjorn a teria adaptado ao Meridiano de Perpignam.

É interessante notar que este novo método, de construção de Tábuas Astronômicas, as "Sizígias", nas quais as posições do Sol, Lua, Planetas e estrelas são tabuladas com a ajuda da matemática, é considerado uma inovação da Astronomia árabe em relação à Astronomia de Ptolomeu, em que o tamanho e período da orbita planetária estavam descritos e tinham que ser aplicados em ordem para calcular a posição celestial. Nas “Sizígias” estas posições são dadas pelas tábuas para serem usadas durante um determinado período, favorecendo a localização pelo viajante, ainda que fossem válidas apenas para a latitude determinada pelo construtor da Tábua. Por isso várias famílias de "sizígias" foram sendo produzidas desde Toledo até Samarcanda, delimitando a linha do Equinócio, permitindo a aplicação de uma Tábua a outras localidades, desde que realizada a conversão dos dados a partir de cálculos matemáticos. Não se pode esquecer a facilidade que os números árabes representaram para essa atividade.

O texto de Al-Saffãr sobre construção de astrolábios encontrado na Biblioteca da Aljama é considerado um texto escrito com clareza, apresentando sumária descrição do instrumento, com determinação de arcos de altura do Sol ou das estrelas, dos arcos diurnos e noturnos, das horas iguais ou temporais, conversão de uma a outra, determinação de alturas medianas de graus coascendentes, do azimute do Sol ou das estrelas, determinação da latitude, da declinação, da longitude, cálculo da sombra pela altura e vice-versa, cálculo da altura das montanhas, minaretes e coisas que se elevem sobre o horizonte, como diz seu autor, determinação da distância entre dois lugares diferentes, cálculo de ascensões retas e oblíquas, determinação da longitude da Lua e dos planetas terminando com capítulo, de clara intenção e prática astrológica com a equação das doze casas, revolução dos astros, dos nascimentos e seus ascendentes. Ainda se atribui a Al-Saffãr um trabalho de medição em milhas terrestres de um grau do meridiano.

Ibn Al Saffãr também aparece documentado como Qâsim Ahmad b.'Abdallãh b. Uma Al-Gafequi, filho de latoeiro (trabalhador com metal), que tinha um irmão chamado 
Muhamad, célebre por sua habilidade na construção de astrolábio e teria construído o primeiro da Andaluzia.

Segundo Millás Vallicrosa, o texto de Qâsim / Al Saffãr é igual ao traduzido por Johannes Hispanus, citado a seguir, diferindo apenas em relação ao último capítulo destinado a determinar a data do inicio do ano cristão e de cada um dos meses, valendo-se de anotações especiais registradas em um dos círculos do dorso do astrolábio, estabelecendo correspondência entre a data cristã e a muçulmana, em continuidade ao trabalho de Maslama, o que revela um trabalho prático de atualização e observação astronômica, que realiza ou registra, o tradutor e escriba Johannes Hispanus, também tradutor de Avicena e Ibn Gabirol, presentes na relação da Biblioteca da Aljama e que teria sido morto em 1180, em Toledo, em decorrência de movimentos antijudaicos.

Selomó ben Yehuda ibn Gabirol citado como Avicenbron na Biblioteca da Aljama, é outro personagem extremamente rico. Aparece também como Gebirol, Cebrol ou Cebron, nasceu em Málaga (1021), o que lhe acrescentou o cognome há- malaqui (o malaguenho). Foi educado em Zaragoza, na corte de Bañu Hud. Mestre em hebraico e árabe sentia-se atraído pelos problemas da filosofia, moral e metafísica. Foi considerado cabalista pela frase: "as letras representam o corpo místico de Deus enquanto Deus, como se diz, é a alma das letras". ${ }^{18}$ Morreu em 1058, em Zaragoza.

Durante muito tempo foi considerado um pensador árabe (Avicebron) e só no século XIX, a partir dos estudos de Salomão Munk, ficou constatada a origem hebraica deste pensador, apesar de suas obras terem tido pouca repercussão entre os sábios judeus.

Como obra científica, escreveu a "Fonte da Vida" em árabe, traduzido ao hebreu por Yehudá ibn Tibbón. Produzida sob o signo do neoplatonismo de Plotino versa sobre a propagação das substâncias que têm em comum a matéria diferenciada pela forma. Procura na Bíblia dados para sua Cosmologia e astronomia, incorporando elementos de caráter científico à poesia religiosa criacionista: "seguir a ação criadora de Deus ou da Vontade Divina até a alma humana, passando através das esferas", bastante influenciado pela Cabala do Séfer Yesirá (Livro da Criação).

Pelo seu excesso de racionalismo e não referências talmúdicas, a Fonte da Vida recebeu sérias críticas de Abrahão Ibn Daud e certo desprezo por parte da comunidade judaica quando editado. Em 1150, sob a proteção do dominicano Raimundo Gundissalvo, é traduzido para o

\footnotetext{
${ }^{18}$ Scholem, G. (1990) p.61
} 
latim por Gerardo Cremona e pelo judeu Johannes Hispanus ou Johannes ben David Hispanus (também apresentado como Avendaut, antes da conversão). Alcançou seu auge durante o século XIII e XIV entre os teólogos cristãos, sendo, devido às implicações heterodoxas e panteístas de sua metafísica hilemorfista, responsável por uma polêmica entre franciscanos e dominicanos em que:

os primeiros neoplatônicos e agostinianos, como Alexandre do Hale, interessados na doutrina da pluralidade das formas, do primado da vontade de Deus ou da capacidade da alma de ir do mundo sensível ao inteligível, tomavam defesa da obra, enquanto os aristotélicos, como Alberto Magno e Tomás de Aquino, atacando particularmente a concepção da matéria universal (hilemorfismo universal) e da unidade das substâncias, condenavam-na como herética e sem consistência racional ${ }^{19}$.

Outra figura importante deste período foi Abraham bar Hiyya (ou Há-Bargeloni; ou Savasorda, corruptela do nome árabe Sahib, Al Xorta, o chefe da guarda), que também aparece como el Sefardi (1070/1136). Identificado como sendo MOSSE SEFARDI, recebeu o nome de Pedro Alfonso ${ }^{20}$, de Huesca, na hora da conversão. Sua cultura árabe foi adquirida na corte de Banu Hud, de Zaragoza-Lérida.

Nascido em Huesca, com atividades registradas em Toledo e Barcelona, ensinou árabe nas comunidades judaicas do sul da França e norte da Espanha. Responsável por compêndios, resumos e traduções do árabe ao hebreu, além de influenciar Maimônides, Hyya aparece ao lado de Ibn Ezra como corrente inovadora orientada no sentido de criar um vocabulário em hebreu para o novo conhecimento que estava sendo vertido do grego para o árabe.

Aparece na Inglaterra como médico do rei Henrique I (1100-1135), exercendo magistério sobre a nova ciência astronômica e matemática de origem arábico-hindu, sendo seus discípulos Walcher de Malvern e Adelardo de Bath. Difundiu na Europa ocidental a técnica do astrolábio para observação astronômica, empregado na atualização das Tabelas astronômicas de al-Jawarizmi e na recensão de Maslama, feitas por ele em Córdoba.

Seu nome está relacionado a muitas obras, entre elas: Fundamento da Inteligência e Torre da Crença (referenciado por Maimônides), Tratado de Geometria e Medição (por meio do qual a Europa cristã teria aprendido Geometria); Livro de Cálculo da intercalação, em que determina as datas do calendário judeu e contém fragmentos da obra perdida de Ishaq

\footnotetext{
${ }^{19}$ GUINSBURG, 1968, p.331.

${ }^{20}$ Petri Anfulsi/ Pero Alfonso/ Petrus Alfonsi. Batismo na Catedral Huesca, tendo como padrinho o Rei Alfonso I, o Batalhador, rei de Aragão, de quem era médico.
} 
Albaliáa $^{21}$ (1035-1094). Traduziu ao latim, com colaboração de Plato Tiburtinus (ou Platon de Tivoli. 1134/1135) as obras de Ibn Al-Saffãr e dedica sua obra ao amigo Johannes ben David, o Hispanensis, o mesmo que traduziu a obra de al-Mayriti, acima citado.

Para Hyya, a finalidade da ciência está sempre subordinada aos fins transcendentais e supremos da religião revelada, de modo que as várias ciências são os fundamentos sobre os quais descansa o Edifício ou Torre da Ciência, conciliando ciência e religião em benefício desta última. Defende uma astrologia instrumental separada da base doutrinal. Eleva o hebreu à categoria de língua científica.

Outro personagem que terá seu nome repetido ao longo da história será ABRAHAM ibn EZRA, (n.1093, Toledo. m.1167, em Roma ou Calahora, nos Pirineus). Seu antepassado, Mosse ibn Ezra (n. Granada entre 1055 / m. após 1135), faz parte de uma família de vizires, discípulo de Ishaq ben Yehuda ibn Gayyat (geração após Gabirol) foi rabino de Lucena, cidade judaica, com cargo na corte do rei de Granada Abdal'1ãh (1077-1090), como chefe da guarda. Como autor, realiza ensaio critico sobre a poesia hebraica espanhola. Após invasão almorávida em Granada emigra para Castela, Navarro, Aragão e Barcelona.

Considerado como a "encarnação judaica do vagante medieval" Ibn Ezra foi estudioso preocupado com o problema de contrastes do sistema astronômico. Passa grande parte de sua vida viajando, chegando até o Oriente Próximo. Consta que exerceu docência científica (1140-1167) entre hebreus e cristãos em cidades como Roma, Salerno, Luca, Pisa, Mântua, Verona, Beziers, Provença, Narbona, Burdeos, Angers, Dreux, Londres e Winchester. Entre suas obras encontramos: "Fundamenta Tabularum astronomicarum", redigida em Dreux, em 1154, considerado como uma recensão bastante ampliada das Tábuas Pisanas de 1145, também por realizadas ele.

Em 1160, produz na Inglaterra, um Tratado sobre Astrolábio esférico, escrito em hebreu. Fez tradução do comentário de Ibn-al-Mutamma sobre as Tábuas Astronômicas de Muhammad ibn Musa al-Jwarizmi. Também é autor do popular trabalho de astrologia Sefer Há-Olam, cuja cópia Jafuda Cresques comprou do físico Lléo Mosconis, em outubro de 1377.

\footnotetext{
${ }^{21}$ ISHAQ BEN BARUK ALBALIÁ (1035-1094) Tio materno de A. ben Daud (Avendaut). Ativo em Granada com Samuel Nagrella é apontado como estudioso do Talmud e da ciência grega. Entre suas obras encontra-se o "Tractado sobre a Intercalación del Calendario" também conhecido como "Secreto de la Intercalación", dedicado a Yosef Nagrella, filho de Samuel Nagrella. O original de sua obra encontra-se desaparecido e é conhecido apenas pelas citações de Abraham Ibn Ezra e de Abraham bar Hiyya, no Sefer há Ibbur.
} 
Muito citado por Benjamin de Tudela, por sua vida de longas viagens como rabi, por várias comunidades, é citado também como almoxarife do Rei Alfonso VII (1126-1157) de Castela.

Produziu obras em várias áreas do saber, tendo escrito mais de 200 livros. Sua produção científica, considerada muito a frente de seu tempo, racional e arrojada em suas conclusões astronômicas e matemáticas, apresenta forte temor supersticioso que o leva a mergulhar na especulação cabalística, ora realizando leituras aristotélicas ora platônicas. Recebe influências de Ibn Gabirol, com quem participa do fascínio metafísico pelos misteriosos âmagos neoplatônico e de sua concepção de Deus carregada de panteísmo.

Seu Universo é composto de três mundos hierarquizados, sendo que no superior a Emanação Divina ou Inteligência Superior atinge os Anjos e a Alma Humana, propagando-se em direção à esfera intermediária, onde ficam os corpos celestes, planetas e estrelas fixas até a esfera inferior, a dos quatro elementos e dos produtos de suas diferentes combinações.

Esta esfera inferior estaria centrada no Homem que, como um Microcosmos, tem em si a representação do Universo materializada em suas três Almas: a vegetativa, do crescimento, a animal, do movimento e a racional, esta propriamente humana, derivada diretamente do Mundo Superior e que permite ao Humano chegar à esfera da verdade, a Deus. O conhecimento de Deus é a mais importante atividade humana e para alcança-la o Homem precisa conhecer a si mesmo e às ciências naturais. Conhecendo-se, portanto, pode remontar a um verdadeiro conhecimento do mundo e de seu Criador.

É comum, na bibliografia selecionada, comparar Ibn Ezra e bar Hyya. Ambos foram sábios conceituados, viajaram pela Inglaterra, pelo norte da França, Castela e Aragão, além de vários outros locais como rabinos. Como filósofos defendiam um pensamento racional, sendo necessário o conhecimento matemático e geométrico para um bom conhecimento da Criação, assim como sua constante atualização. Ezra, porém, faz leituras tanto aristotélicas como platônicas, realizando especulações cabalísticas que o colocavam em oposição a Hyya e pensadores como Yehudá ben Barzilay representante de uma modalidade conservadora inclinada à utilização de fontes astrológicas e científicas exclusivamente hebraicas. ${ }^{22}$

Em relação à polêmica sobre se o trabalho destes autores seria apenas de tradutores da chamada "ciência árabe", encontra-se em Zonta (2004) e Scholem (2008) tanto a confirmação deste trabalho de tradução, compilação e divulgação das fontes árabes entre cristãos e hebreus do Ocidente como a afirmação de protagonismo no que chamam de "renascimento científico

${ }^{22}$ SELA, 2008,p.261-290. 
europeu do século XII". Considerando como contribuição da ciência hebraica na Espanha o desenvolvimento da aritmética, geografia, astronomia e medicina, enfatizam o importante papel desta Comunidade, devido à atualização dos conhecimentos e de uma crescente participação a partir do contato mais estreito com a Europa cristã, principalmente na área prática de observação astronômica e médica.

O terceiro personagem destacado da Biblioteca da Aljama, Maimônides ou Rabi Moseh ben Maimón ou RaMBaM ou Abu Imram Musa ben Maimon, nasceu em 30.03.1135, em Córdoba, originário de família ilustre, de eruditas renomados, remontando a Iehudá há-Nasi, da Casa Davídica. Morreu em 1204, no Cairo onde foi Rabi bastante conceituado.

Seu pai, Maiomon ben Iossef, dayyan, juiz, na Aljama de Córdoba e ilustrado talmudista, astrônomo e matemático, abandonou esta cidade devido às imposições de conversão ou morte imposta pelos Almohadas, sob o governo de Ibn Tamur (1148). Passou toda uma década vagando pela Espanha, fixando-se em Fez, no Marrocos (1160) com as famílias de Yosef Quimhi, gramáticos e exegetas e a família de Yéhuda ben Tibbon, tradutores, que pertenciam à mesma Comunidade e que os acompanharam pela Espanha, dirigindo-se para o Languedoc quando a família de Maimônides se encaminha para o Marrocos e Egito.

Nas discussões sobre a posição a ser tomada frente a conversão, expulsão ou morte, Maimônides se posiciona, em sua Epístola sobre a Apostasia, pela conversão fingida. Polêmica que levou a vida de Rabi Yehuda ibn Sosãn, rabino de Fez, preso e executado na forca por sua fidelidade ao judaísmo. Maimônides, sob a proteção do teólogo muçulmano Abu-1-àrab ben Moisa, imigra com a família para a Palestina, em 18 de abril, passando pelo Egito, Alexandria e chegando a São José de Acre em 03 de Maio de 1160. Exerceu a função de médico da câmera do vizir Al-Fadl e do próprio sultão Saladino (1137-1195) e de seus familiares.

Apresenta sua produção como vocação para aprofundar-se nas ciências e na problemática filosófica, segundo a doutrina aristotélica e demonstrar a conciliação que cabe estabelecer entre a Razão e a Revelação (a ciência verdadeira e a religião) ou entre a Bíblia, a filosofia e as ciências.

Realizou produção toda em árabe, considerada no momento a língua veículo da cultura científica. Dentre sua produção literária destacamos: Cálculo da Intercalação (Hěsbón ha 'Ibbur), elementos para a elaboração do calendário judaico, livro em que Maimônides revela 
acreditar que uma preparação matemática astronômica conveniente deveria preceder o acercar-se de problemas filosóficos. Nesta arte, teve como discípulo Yosef ben Yehuda, presente em Toledo. Uma de suas obras mais importantes foi Guia dos Perplexos, no qual desenvolve discussão sobre a revelação bíblica e a filosofia, entendida então como um conjunto de ciências de tendências aristotélicas, com objetivo de esclarecer a organização cosmológica, livro presente na Biblioteca da Aljama.

Como havia o constante deslocamento de rabinos e estudiosos, com eles iam livros e ideias. Rapidamente ocorre a difusão dos escritos de Maimônides pelo sul da França, Provença, levados pelos Tibbonidas família de tradutores iniciada por Yehuda ben Saul ibn Tibbón, nascido em Granada e morto em Marselha (1120-1190), considerado "o pai dos tradutores", além de médico e possuidor de valiosa biblioteca. Esta família aparece organizada como tradutores do árabe para o latim ou outras línguas, agindo como divulgadores do conhecimento produzido pela comunidade judaica, apresentando em seu catálogo, além da tradução das obras de Maimônides, tradução de obras de Gabirol, de Saadia ha Gaón, Aristóteles e Averroes.

Toledo merece especial atenção no processo de transmissão do conhecimento. Sob o comando de Afonso X (1252-87), traduziu-se principalmente assuntos científicos, como trabalhos de Al-Kindi, Ibn Sina (Avicena), al-Farabi, Ibn Gabirol, Azarquiel, al-Razi e muitos outros, inclusive sendo preparadas as Tábuas Afonsinas, que indicam a posição e o movimento das estrelas, em Toledo naquele momento. Entre os judeus que colaboraram encontramos Abraham al-Faqui, Judah ben Mosé ha-Kohen, Samuel Levi Abulafia, profundos conhecedores do árabe e do românico, herdeiros da velha tradição hebraica. Com efeito, os estudos talmúdicos floresceram em Toledo, devido à importante imigração causada pela presença Almohada na Andaluzia em meados do século XII, tornando a comunidade judaica de Toledo a mais célebre da península.

Romano (1996) para fazer frente a afirmações genéricas quanto a esta importância, elabora uma tabela relacionando tradutores e retradutores, chegando à conclusão de que na relação de doze pessoas que intervieram nas traduções afonsinas, cinco eram judeus, o que equivale a $42 \%$ dos colaboradores e, refinando a pesquisa, afirma que a produção destes colaboradores simboliza $74 \%$ da produção realizada na chamada Escola de Tradutores de Toledo e que a obra mais importante deste período, as Tabelas Afonsinas, foram feitas pelos 
dois principais colaboradores judeus, Yehudá e Ishaq, sem nenhuma participação de cristãos ou do próprio rei Afonso, que colaborou em obras relacionadas à literatura e religião.

Yehuda ben Mosé (ben Mosca) há-Kohén é o mais conhecido e estudado dos participantes de Toledo. Considerado físico, o que implicava em pelo menos duas áreas de saber, a medicina e a astronomia, conhecedor do árabe e do latim realizou versão de livros relacionados à astronomia, importantes para o momento como o Lapidário, Alcora, Libro de las Cruces, o Picatrix e revisão do Tratado sobre as Estrelas Fixas. A família Kohén estará presente na Maiorca do século XIV.

Ishaq ben Sayyd, cuja grafia apresenta-se de vária maneiras: Rabi Çag; Rabi Çag de Toledo ou Rabi Çag aben Cayut que pode ser corrigida em aben Çayt ${ }^{23}$. Zacuto o apresenta como R. Ishaq ben Sid, o "hazzam de Toledo" (cantor de Toledo). Está documentado como fabricante de relógios e instrumentos de observações astronômicas, conhecedor do árabe, do hebraico e do latim, comentou os eclipses do Sol e da Lua observados por Isahq Israeli, redigiu textos sobre a construção e uso de relógios e instrumentos e os quatro primeiros capítulos de La Alcora. Recebeu a missão de construir o Quadrante Sennero. Aparece também relacionado às novas tabuas pisanas, no mesmo período, isto é, entre 1263 e 1272, momento da confecção da carta Portulano mais antiga, a Carta Pisana.

De Don Abraham só temos o prenome e o registro de sua posição de magister, físico e alfaquim (médico). ROMANO (1996) propõe Abenxuxen como nome de família. É responsável pela tradução do Líber de Mundo et Coelo e de La Açafeha, conhecedor do árabe e participante das traduções da Escala de Mahoma. A Família Abenxuxem estará presente em Maiorca durante o século XIV.

Este momento em Toledo e sua divulgação são importantes, pois ocorrem próximo ao momento de construção do Padrão Portulano, com certeza dando elementos teóricos para seu desenvolvimento.

Na corte de Barcelona também houve a formação de uma equipe de tradutores, sob a proteção dos reis de Aragão. Encontra-se documentado o Mestre YAHUDA, filho de Astrug Bon Senyor, médico de Jaime II, que redigiu: "Libre de paraules e dits de savis e filosofs", em Barcelona, 1298, e realizou a tradução catalã da obra de cirurgia de Al-Zwhrawi, também na Biblioteca da Aljama.

${ }^{23}$ (ROMANO: 1996) 
Na primeira metade do século XIII, em Barcelona, está documentado Abraham ben SemuelL ben há-LEVI ibn HASDAY, como autor da obra "El hijo del rey y el monge" adaptação hebraica da vida de Buda e como tradutor do "El libro de los Elementos", de Ishaq Israeli, astrônomo, o mesmo que aparece relacionado a Dunas Ben Tamim, chamado a Córdoba, no século X. Livro constante da Biblioteca da Aljama.

Percebe-se nesta personagem a união dos patronímicos Hasdai e Levi. A família Levi terá vários representantes relacionados às cortes e à produção cultural como: Yehudá ben Samuel ha-Levi (n.1075, Toledo), médico e ministro do Rei Alfonso VI; Samuel há-Levi, documentado na Toledo afonsina (junho 1276/maio1279) com a obra "Relógio de la candeia" e como membro da equipe que revisou a tradução do "Tratado sobre as Estrelas Fixas" e a produção das Tábuas Afonsinas, em Toledo.

Talvez a personagem mais importante em Aragão tenha sido Hasday Abraham Crescas. (n.Barcelona 1340-1410), descendente de família de sábios, segundo alguns a mesma de Cresques Abraham, estando documentado, desde 1373, como conselheiro do Rei de Aragão para assuntos relacionados à comunidade judaica. Em 1387, Juan I concede a ele a faculdade de excomungar os judeus que transgredissem suas leis. Seus amigos de Zaragoza, os Irmãos da Cavalaria, o chamam para ocupar o posto de Perfect, rabino de Zaragoza de 1372 a 1386, quando vai para Valência. Chegou em 1389 e, em 1390, por sua amizade com Juan I e sua mulher dona Violante, foi nomeado primeiro juiz dos malzines (delatores) e logo como juiz único e supremo de todas as aljamas de Aragão.

A relação de Hasday Cresques com os Irmãos da Cavalaria é antiga e aparece em outros momentos, se nos utilizarmos da informação de que Cresques Abraham é também Elisha Benevistes $^{24}$. Uma carta do Mestre Racional da corte de Pedro IV, o Cerimonioso, revela que Juan de Aguilar, correio de Zaragoza, reconhece ter recebido pagamentos de Beneviste da Cavalaria, judeu da cidade e coletor das primícias do arcebispado de Zaragoza.

Sua autoridade chegou a ser extraordinária. Graças a ela e ao fato dos reis se encontrarem em Zaragoza durante o verão de 1391, sua comunidade não foi destruída, como ocorreu a quase todas da Espanha, inclusive a de Aragão. No evento, Hasday perde, em Barcelona, seu único filho.

\footnotetext{
${ }^{24}$ Conforme assinatura constante da Biblia Fahri, obra assinada por Cresques Abraham em que assume o nome religioso de Elisha Benevistes.
} 
Honorius Augustuduniense ${ }^{25}$, a personagem mais citada pelos estudiosos como base do texto Cosmológico do Ms. Esp.30, que apresenta trechos iguais ao seu Imago Mundi, oferece outro interessante exemplo de rede.

Yates (1960), em estudo no qual pretende demonstrar a influência da Teoria dos Elementos de Scotus Erígena sobre o Tratado de Astronomia de Ramóm Lull, detecta influências, nos dois escritos, tanto das categorias aristotélicas como das Sephirot dos hebreus.

Erígena, nascido na Irlanda durante o século IX, sabia grego e traduziu para o latim Pseudo Dionísio, monge sírio do século VI e produziu o livro De Divisione Naturalis ou Periphiseon, uma síntese entre o pensamento grego e Santo Agostinho.

Parecendo conhecer apenas Timeo, de Platão, foi considerado neo-platônico, por defender que tudo é geração, tempo e espaço através do movimento dos Elementos, sendo o verbo Divino começo e fim de tudo e o Humano elemento de ligação entre as esferas, dento da ideia de Cosmos e Microcosmos, em movimento eterno, não existindo uma ordem preestabelecida em suas causas.

Honorius Augustuduniense estudou em Canterbury e escreveu Imago Mundi, no inicio do XII, em Regensburg, uma provável comunidade de monges irlandeses, retomando e acrescentando dados ao estudo de Erígena, popularizando seu trabalho. Ramon Llull produziu sua obra no final do XIII, em Maiorca, tendo em seu histórico várias viagens à Inglaterra e, segundo Yates (1960), teria lido Erígena a partir de Honorius.

Llull pensa o Firmamento em sentido astrológico, ou seja, planetas, signos do Zodíaco e possíveis relações entre as esferas, incorporando de Erígena os elementos relacionados à Ciência grega, principalmente o método de observação, os instrumentos astronômicos e alguns elementos da Astrologia, aceitos por judeus e islâmicos, em relação a influências quanto ao clima, às marés e a medicina astrológica. Aqui cabe um esclarecimento quanto ao termo "ciência grega" entendida como o conhecimento pré-socrático que explica o Universo como uma estrutura racional, capaz de fornecer a lógica secreta para entendê-lo, tendo como questão central o Movimento Primeiro chegando à Geometria esférica e a Trigonometria, transformando as imagens do Zodíaco, herdada dos antigos, em seres geométricos.

\footnotetext{
25 Honorius Augustuduniense, ou de Autum, nascido em 1090, produzindo até 1156, portanto contemporâneo de Ezra e outros autores encontrados na Biblioteca da Aljama.
} 
Além de base para escritos de Honorius e Llull, Erígena teria sido base também para o judeu Avicebron (Gabirol) em seu A Fonte da Vida, presente na Biblioteca da Aljama, escrito em árabe e traduzido ao hebreu na mesma época em que Honorius Augustoduniensis produziu Imago Mundi e Clavis Physicae, considerada uma seleção de textos do De Divisione Natura, de Scotus, momento de intensa troca entre filósofos cristãos e hebreus na Inglaterra e norte da França. A obra de Gabirol foi bastante divulgada entre os filósofos cristãos, despertando o interesse dos seguidores de Agostinho e entre sábios hebreus que realizam especulações sobre o hilemorfismo universal, a relação entre os elementos (hylé) e a criação, com implicações heterodoxas e panteístas a respeito de Deus e da Criação, fonte de polêmicas entre Rabinos e Filósofos hebreus medievais.

Finalizando é interessante destacar que Yates (1960) detecta a presença de Heráclito, o pré-socrático, nos escritos de Erígena, Honorius, Llull e Gabirol em relação ao eterno movimento, a inexistência de um único início e a necessidade de se considerar o ponto de vista do observador. Quanto mais se aprofunda no estudo das fontes medievais, mais difícil fica detectar uma origem precisa das ideias. O trecho inicial do Ms. Esp.30, que realmente reproduz algumas frases do Imago Mundi, pode ter sido copiado de qualquer um dos outros autores que estivessem presentes na Ilha, pois não se entende que, necessariamente, estas poucas frases, bastante aristotélicas em seu conteúdo, ou seja, forma, tamanho e sustentação da Terra, estejam apenas no texto Imago Mundi.

À dificuldade natural existente para identificação das fontes usadas na confecção dos manuscritos medievais, dada a pratica de cópias e comentários não muito preocupados com a identificação de seus autores, no caso da produção do Padrão Portulano e, mais especificamente no caso do Manuscrito Espagnol 30, o “Atlas Catalão" e a produção cartográfica maiorquina, acrescenta-se a questão dos constantes deslocamentos da comunidade judaica produtora deste conhecimento, que, por um lado, dificulta na identificação de seus personagens, uma vez que estes deslocam-se constantemente, devido aos constantes conflitos econômicos culturais e a necessidades próprias da comunidade que procura manter-se como nação a partir das trocas que esses deslocamentos permitem.

De qualquer maneira, por este rápido levantamento das possíveis redes de transmissão do conhecimento necessário para, não só a idealização do padrão Portulano como a confecção dos instrumentos indispensáveis para sua execução pode-se afirmar a efetiva participação da comunidade judaica em todos os passos dados para sua concretização, desde o comércio 
marítimo até a produção dos suportes para seu registro, assim como não se pode deixar de apontar a continuidade desta participação no processo que se segue em termos de produção Cartográfica realizada pelos portugueses e holandeses no processo de transformação do Atlântico em território comercial. 


\section{REFERÊNCIAS}

CAMPBELL, T. (1986). "Census of Pre-Sixteenth Century Portolans Charts", Imago Mundi, 38, pp.67-94.

CAMPBELL, T. (1987): "Portolan charts from the late thirteen century to 1500", en J.B. Harley y D. Woodward eds., The History of Cartography. Chicago-Londres: The University of Chicago Press. vol 1.

CATEURA BENNASSSER, P. (1989): "Las instalaciones portuarias de la Ciudad Mallorca (1300-1350)", en XIII Congreso Histórico de la Corona de Aragón, Barcelona. Comunicación I, pp.49-60.

COWAN, J. (1996): O sonho de um cosmógrafo. Meditações de Fra Mauro na Corte de Veneza do século XVI. RJ: Rocco.

FALL Y.K. (1982): L`Afrique à la naissance de la cartographie moderne. Les cartes majorquines: XIV-XV siècles. París: Karthala.

GUINSBURG, J. (1968): Do Estudo e da Oração. São Paulo: Ed. Perspectiva.

LANE, F.C (1963). "The Economic Meaning of the Invention of the Compass". In The American Historical Review. Vol.LVIII, n.3 Abril p.605-617

LE GOFF, J. (2006) Os intelectuais na Idade Média. Rio de Janeiro: José Olimpio. $2^{\text {a }}$ ed.

MillaS VALliCROSA, J. M. (1960). Nuevos Estudios sobre Historia de la ciencia española. Madri/ Barcelona: Consejo Superior de Investigações Científicas (C.S.I.C). Edición fac-símile.

MILLAS VALLICROSA, J.M. (1973): Literatura hebraico española. Buenos Aires: Editorial Labor.

NOGUEIRA, M.G ( 2013) O Manuscrito Espagnol 30 e a Família do judeu Cresques Abraham. Um estudo sobre as fontes da Cartografia maiorquina. Tese Doutorado/ USP.pdf.

PUJADES I BATALLER, R.J. (2008): Les cartes portolanes. La representació medieval d'una mar solcada. Barcelona: Enciclopèdia Catalana, SAU

REY PASTOR, J. y GARCIA CAMARERA, E. (1960): La cartografía Mallorquina. Madrid: CSIC. 
ROMANO, D. (1996): Los hispanos judaicos en la traducción y redacción de las obras científicas alfonsíes. Toledo: Escuela de Tradutores de Toledo-Diputacción Provincial de Toledo.

ROMANO, D. (1983): Judíos al servicio de Pedro el Grande de Aragón (1276-1285), Barcelona: Institución $<<$ Millá i Fon-tanals $>>$

SANTARÉN, V. (1844): Atlas composé de mappemonde, de portulans et de cartes hydrographiques et historiques. Paris: Ed. Thumot et Cie.

SELA, SHLOMO. (2008). "Dos textos astrológicos conservados en el comentário al Sefer Yesirá de Yehuda ben Bazilay al-Bargeloní” pdf. SEFARAD. Vol.68:2, Julio-diciembre 208 pgs.261-290.

SCHOLEM, G. (1990). A Cabala e a Mística Judaica. Lisboa: Publicações D.Quixote.

URGELL DE HERNANDEZ, R. (dir.) (2010): Llibre dels reis: Llibre de Franqueses $i$ privilegis de Mallorca. Códex 1 de l’Arxiu del Regne de Mallorca: estudis i transcripción. Palma de Mallorca: Universidad Illes Baleares.

YATES, F.A. (1960) "Ramom Lull and John Scotus Erigena". Journal of the Warburg and Courtauld Institutes. Vol.23. n.1/2 (jan.jun. 1960).

ZONTA, M. (2004). "La Scienza di Al-Andaluz nel secolo XII”. In Boletín de La Asociación Española de Orientalista, XI. ps. 59-64. Ciência hebraica no Andluz.pdf. acesso: 04.03.2012 